NBER WORKING PAPER SERIES

\title{
THE IMPACT OF POLLUTION ABATEMENT \\ INVESTMENT ON PRODUCTIVITY CHANGE: \\ AN EMPIRICAL COMPARISON OF \\ THE U.S., GERMANY, AND CANADA
}

\author{
Klaus Conrad \\ Catherine J. Morrison
}

Working Paper No. 1763

NATIONAL BUREAU OF ECONOMIC RESEARCH

1050 Massachusetts Avenue

Cambridge, MA 02138

October 1985

The research reported here is part of the NBER's research program in Productivity. Any opinions expressed are those of the authors and not those of the National Bureau of Economic Research. 
NBER Working Paper \#1763

November 1985

The Impact of Pollution Abatement Investment on Productivity Change: An Empirical Comparison of the U.S., Germany, and Canada

\section{$\underline{\text { ABSTRACT }}$}

It has often been asserted that imposition of environmental regulations in the 1970's may be a partial explanation for the productivity growth slowdowns experienced by most industrialized countries during that decade. The contention is that expenses incurred to satisfy these regulations, such as investment in pollution abatement capital, is unproductive in terms of measured output. Thus conventional productivity measures will be biased downward when such regulations are imposed. In this paper we construct a model which explicitly recognizes the difference between pollution abatement capital and "productive" capital and then use this framework to devleop an adjustment to nonparametric measures of productivity growth, purging them of the bias resulting from regulation. We measure the bias for the manufacturing sectors of three countries, the U.S., Canada and Germany, and thereby assess the impact of increased pollution abatement capital regulation on productivity growth. Our principal finding is that the bias, which depends on relative rates of growth of output and pollution abatement capital investment, is modest.

Klaus Conrad

University of Mannheim

Lehrstuhl fur Volkswirtschaftslehre

Insbesondere Mikrookonomie

D-6800 Mannheim 1

Seminargebaude A5

West Germany
Catherine J. Morrison Department of Economics Tufts University Medford, MA 02155 


\section{Introduction}

The imposition of environmental regulations has of ten been suggested as a partial "explanation" for the productivity growth slowdown experienced by most industrialized countries in the early 1970's. The contention is that investments are foregone because resources that otherwise would be productive must be used to satify the regulations, and the goal of the regulations -pollution abatement - has no marketable and therefore quantifiable effect in terms of productivity. This hypothesis has been explored by researchers such as Denison [1979], who attempted to determine the effects of environmental regulation by first estimating the incremental costs of production due to environmental regulations, and then using these estimates to impute the percentage reduction in output per unit of input attributable to regulation. Similarly, Norsworthy et al [1979] assessed the impact of environmental regulations by removing the pollution abatement capital component of total capital input to purge the capital measure of "unproductive" capital. Gollop and Roberts [1983] instead included regulation in a long run total cost function and used econometric estimates of the production technology to determine the biases resulting from regulations. Some researchers including crandall [1980] and Christiansen and Haveman [1981] emphasize the impact of more indirect and difficult to quantify impacts of regulations, including discouraging otherwise productive investments and technological innovations.

It has also been asserted that environmental regulation may instead facilitate economic growth. This hypothesis has been suggested by Meyers and Nakamura [1980] who use a putty-clay model to show that it is possible for increasingly stringent environmental regulation to cause more capital turnover, and therefore modernization, so that the net effect may be increased productivity growth. 
Finally, some researchers have recently focused on the impacts on international competitiveness of environmental regulations and resulting low productivity growth in the U.S. An important example of this is Kalt [1985] who asserts that the U.S. is at an extreme disadvantage in international markets because of the depressing impacts of environmental regulations, especially since regulations in the U.S. are so cost--ineffective.

It is clear that there is a wide range of methods and focuses in studies about the impact of environmental regulations on productivity, and no clear consensus of the magnitude -- or even direction -- of the impacts, how to quantify these impacts, or what the international effects of the regulations may be. In addition, the impact of these regulations has not, generally, been motivated within an explicit model of the behavior of firms when faced with regulations on a resource which, without regulation, is a free good to the firm. Most existing models which consider the impacts of regulation on productivity growth calculations, either adjust output or input in an ad-hoc manner, or simply consider regulation to be an additional input into the production process and use an econometric model. Other studies are not, strictly speaking, based on a theoretical model but instead assess as many costs of regulation as are quantifiable given available data. Virtually no studies then place these estimates in an international context that allows comparison of the relative impacts of regulation on productivity growth across countries.

In this paper we develop a model of the decisions of a firm facing a standard for pollution emissions, which explicitly recognizes the effects of environmental standards and resulting pollution abatement capital investments. This model permits consideration of the explicit and implicit costs of purchasing pollution abatement capital to satisfy these regulations, and the values to the firm of compliance with the regulation. The framework incorporates the notion that the pollution abatement capital is not productive 
in the usual sense; it is unproductive in terms of measured output and therefore should not be treated like a productive input for productivity calculations.

The implications for measurement of productivity growth from the theoretical model incorporating pollution abatement capital investment are straightforward to implement nonparametrically, and are therefore useful for applied researchers. The resulting impact on measured productivity growth as compared to the measurements generated by traditional methods is, however, theoretically ambiguous. The costs incurred from pollution abatement capital purchases are separated from production capital costs, so any upward bias in capital growth from sudden increases in poliution abatement capital investment is purged. The benefits accruing to expenditures on pollution abatement capital are implicitly also taken into account; they are represented by a shadow value characterizing the value of the standard at the margin. 1 This value, which is equivalent to the cost of pollution abatement capital on the margin, is incorporated as an adjustment to the weight on output change in the productivity measurements. This may counteract the capital change impact. Thus, as recognized by Meyers and Nakamura, the impact of environmental regulations is an empirical issue which depends on which effect dominates.

Perhaps the most important contribution of the current study is not the framework -- even though the theoretical justification of the adjustment process for productivity measurement is very important -- but the comparison between the manufacturing sectors of three important industrial countries, the U.S., Canada, and Germany. This comparison allows consideration of the relative impacts of environmental regulations among the three countries, and therefore of the impact

\section{1.}

Theoretically this value could be interpreted as an implicit measure of some of the indirect costs of regulations including regulation-induced inefficiency from discouraging technological innovation or other more productive investment which would have a higher shadow value. Empirically these effects cannot be distinguished, however, because the data available cannot usefully distinguish between the ex-post returns to the two types of capital. 
on international competitiveness of these regulations. The alternative ways countries have dealt with environmental concerns, and the resulting effect on relative production growth, can therefore be assessed in this framework.

Note finally that the methods here, as for any productivity measurement studies which explicitly are based on a model of the production process, do not recognize pollution abatement as a beneficial "output". It is clear that if environmental impacts were marketable, "returns" to abatement would compensate ... to a greater or lesser extent-- for the decrease in marketed output.

Production-oriented studies cannot assess the social benefits from abatenent, but the theoretical framework for this study, through the shadow valuation of the capital investment required for abatement, does provide an implication about how to assess the implied value society has placed on environmental protection by imposing standards. This information could be used, if benefit data were available, to determine whether the standards imposed on the industry were at the appropriate level to facilitate social optimization.

The paper proceeds in Section II by developing the theoretical model used as a basis for the approach, and the resulting implications for productivity measurement. Section III then presents and discusses standard and pollution abatement capital-adjusted productivity indexes, and average yearly percentage productivity growth rates, for the manufacturing industries of the U.S. in 1960-80, Canada in 1967-80 and Germany in 1972-81. The final section includes concluding remarks and suggestions for further research.

\section{I1. Model specification}

The model of firm behavior including environmental standards is in the spirit of conrad [1985] and Dasgupta [1982]. The firm's production decision is assumed to be based on the maximization of profits by the choice of output (x), 
variable inputs $\left(v_{j}\right)$, and investment in both productive capital ( $I$, with stock level K) and pollution abatement capital (IPA and KPA). This problem can be written as:

1) $\max _{x_{t}, I}, I P A_{t} \sum e^{-r t}\left(p_{t} x_{t}-G\left(x_{t}, K_{t}, q_{t}\right)-P I\left(I_{t}+I P A_{t}\right)\right.$

subject to

a) $K_{t+1}=K_{t}+I_{t}-\delta K_{t}$

b) $K P A_{t+1}=K P A_{t}+I P A_{t}-\delta K P A_{t}$.

c) $T E_{t}=\xi x_{t}$

d) $\overline{\mathrm{NE}}_{\mathrm{t}}-\mathrm{f}(\mathrm{KPA}) \cdot \mathrm{TE} \geqslant 0$,

The maximization process represented by (1) is standard, where $p_{t}$ is the price of output at time $t$ so $p_{t} x_{t}$ is equal to revenue, $G(\cdot)$ is the variable cost function representing the optimized choice of variable inputs for any given $x_{t}$, $K_{t}$ vector and input prices $q_{j}$, and $P I$ is the common asset price of investment. goods so PI( $\left.\mathrm{I}_{\mathrm{t}}+\mathrm{IPA}_{\mathrm{t}}\right)$ is the expenditure on investment in both types of capital. Note that the variable cost function is assumed to depend on $K$ but not KPA since KPA is not productive. (1a) and (1b) also are typical definitions. (1c) and (1d), however, require some explanation.

(1c) represents the flow of pollution from the production process without regulation. TE stands for total emissions, in this sense the unabated total rate of discharge of pollutants. $\xi$ is an emission to output parameter which represents the constant proportional relationship between pollutant discharge and production when no standards and therefore no pollution abatement capital exist. The reduction of emissions requires additional costs associated only with pollution abatement. This reduction therefore is a function of the level 
of pollution abatement capital, KPA, and is represented by $f(K P A)$. The resulting level of emissions, denoted non-abated emissions (NE) is characterized by (1d), where NE is the standard set for allowable emissions. $f(K P A)$ is a positive but decreasing function since increasing the pollution abatement capital stock causes the amount of emissions to decline; $f^{\prime}(K P A)<0$. In addition, the second derivative of this function should be positive so that the contribution of incremental units of KPA diminishes as the stock of KPA increases; and $f(\infty)=0$ so that if $K P A \rightarrow 0, N E=0$.

Note that this model does not require knowledge of the stock of pollutants because regulation is assumed to be on emissions. This can be adapted to apply to regulations about the existing stock instead of flow of emissions as developed by Dasgupta [1982]. Note also that this approach does not require a damage function because valuation of the damage is implicitly incorporated in the specification of the standard, although a damage function can be incorporated in a straightforward manner ${ }^{2}$. The balance of the (private and social) benefits received from production and the costs imposed by the pollution are therefore captured by the profit function and the constraint and corresponding shadow value, respectively .

The constrained maximization facing the firm from (1) can therefore be writtẹn as :

2) $\max _{x_{t}, I_{t}, I P A} \sum e^{-r t}\left\{p_{t} x_{t}-G\left(x_{t}, K_{t}, q_{t}\right)-P I\left(I_{t}+I P A_{t}\right)\right\}-\tilde{\tau} \cdot\left(f(K P A) \cdot \xi_{t}-\overline{N E}\right.$, subject to (1a) and (1b). type of function where the marginal damage is very large in the neighborhood of a given level of emissions (in the Dasgupta framework, the stock) these two approaches are equivalent. 
We assume both $K$ and KPA, the state variables, as well as output, $x_{t}$, are chosen by the firm in each time period to optimize (1). The first order

conditions for the control variable $x_{t}$ and the state variables $K_{t}$ and $K P A_{t}$ which capture the investment paths $I_{t}$ and IPA $_{t}$ can therefore be written as:
3a)

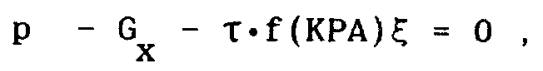
so
$p_{t}-\tau \cdot f(K P A) \xi=G_{x}$
b) $-P I(r+\delta)-G_{K}=0$,
so
$q_{K}=-G_{K}$, and ,
c) $\quad-P I(r+\delta)-\tau \cdot f^{\prime}(K P A) \xi x=0$,
so
$q_{K}=-\tau \cdot f^{\prime}(K P A) \xi x$,

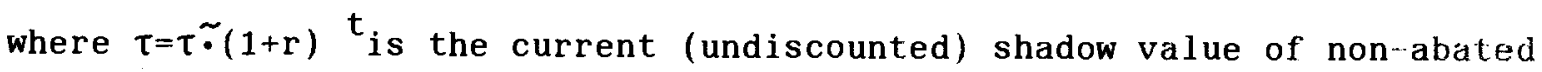
emissions, and $q_{k}$ is the rental price of capital goods (the ex-post price) which is assumed the same for both KPA and $K$ because PI, $r$, and $\delta$ are assumed the same. 3 Note that even though this approach is based on long run analysis, if $q_{K}$ is calculated as the ex-post price the analysis is consistent with a story based on slow adjustment; the capital stocks are evaluated at their shadow values rather than their ex-ante prices which may not reflect the true marginal product.

These first order conditions provide interesting inferences. (3a), for example, captures the typical assertion in the pollution literature that additional revenue with a change in output must cover both the change in production costs and the extra required costs of abatement on the margin; "extra" profit must be made to pay for pollution abatement capital expenses associated with production. $\tau$ is positive because it represents a cost to the firm - an emission charge reflecting the undesirable effects of pollution. The

3

This assumption is not necessary for the analysis, and in some cases it may not be justified. If it is not used, however, the return to the two types of capital cannot be identified individually and non-parametric methods of analysis cannot be used. In this case econometric analysis to separately identify the shadow prices of $K$ and KPA would be necessary. See Berndt and Fuss [1985] for a discussion of the importance of evaluating the contribution of fixed inputs by their shadow values. 
firm will therefore reduce production from that which it would choose without regulation; it will try to maximize, not simply profit from production, but profit net of emission charges. (3b) says that $q_{k}=-G_{K}$ is the value of having more capital in terms of using less inputs to produce a given output -- the shadow value of capital discussed by Lau [1978]. (3c) is the corresponding shadow value determination equation for KPA, including the recognition of (i) the social valuation of pollution -. or the damage resulting from the pollution -- represented by the standard, and (ii) the nonproductive nature of the pollution abatement capital stock represented by the lack of a $G_{\overline{K P A}}$ term. More specifically, the shadow value of $K P A,-\tau \cdot f^{\prime}(K P A) \xi x$, is a foregone "tax" that would implicitly have had to be paid to compensate society for not meeting the standard.

$\tau$ is an important parameter in this analysis. It captures the shadow value -- in terms of costs -- of non-abated emissions. In particular,

$$
\text { 4) } \begin{aligned}
\overline{\mathrm{NE}}-\mathrm{f}(\mathrm{KPA}) \xi \mathrm{x} & >0 \rightarrow \tau=0 \\
& =0 \rightarrow \tau>0
\end{aligned}
$$

Thus if the constraint is not binding, i.e., if $\overline{\mathrm{NE}}>\mathrm{f}(\mathrm{KPA}) \xi \mathrm{x}$, the valuation of the constraint at the margin, $\tau$, is zero. This shadow valuation of the constraint, $\tau$, has an interesting interpretation. If a standard exists and it is binding, $\tau$ represents the standard because it values the standard at the margin. It can therefore be interpreted as the implied tax rate or marginal valuation of the damage function that would cause the required level of abatement, which satisfies the standard, to be met. Note that $\tau$ does not represent a tax schedule or damage function except at the margin; it is an implicit valuation balancing the private costs of satisfying the standard and the social benefits from attenuating the damage of the pollutants which prompted the standard. 4 
$(3 a, b, c)$ can be rewritten to facilitate consideration of the homogeneity properties of the functions as:

5a) $\frac{p \cdot x}{G}-\frac{\tau \cdot f(K P A) \xi x}{G}=\frac{p \cdot x}{G}-\frac{\tau \cdot N E}{G}=\frac{\partial \ln G}{\partial \ln x}$,

b) $-\frac{q_{K} \cdot K}{G}=\frac{\partial \ln G}{\partial \ln K}$, and ,

c) $\frac{q_{K} K^{K P A}}{G}=\frac{-\tau \cdot f^{\prime}(K P A) \cdot K P A \cdot \xi x}{G}=\frac{\tau \cdot N E}{G}$

Note that the last equality, (5c), requires the $f(K P A)$ function to be homogeneous of degree $(-1)$. This assumption is not necessary to impose for the analysis but is a useful simplifying assumption. It is not possible in general to determine the degree of homogeneity of $f(K P A)$.

The expressions in (5) can be employed to motivate the definition of the total cost function, $C$, and define homogeneity properties of $G$ and $C$. Homogeneity of degree one (constant returns to scale) of $G$ implies that $\partial \ln G / \partial \ln x+\partial \ln G / \partial \ln K=1$ (see Lau [1978]). From (5), this implies that $p \cdot x / G-\tau \cdot N E / G-q_{K} \cdot K / G=1$ for each time period $t$. Rewriting this equality results in $p \cdot x=G+\tau \cdot N E+q_{K} \cdot K$, which, using $(5 c)$, is equivalent to $p \cdot x=G+$ $q_{K} \cdot K P A+q_{K} \cdot K--$ the firm's total costs, C. More specifically, the firm pays variable plus capital costs for production and $q_{K} \cdot K P A$ for the corresponding required pollution abatement. This regulatory cost is equivalent on the margin to the valuation of emitted pollutants to society, so the cost function can be written in terms of either cost. The $\tau \cdot N E$ cost component, however, is implicit. Thus the expression based on this component is not very useful for empirical analysis.

the damage on the margin and can be used to assess the implications of the standard. 
It is easy to show that this implies homogeneity of degree one also for the total cost function defined as $C=G+q_{K} \cdot K+q_{K} \cdot K P A$. I.e., $\partial \ln \mathrm{C} / \partial \ln \mathrm{x}+\partial \ln \mathrm{C} / \partial \ln \mathrm{K}+\partial \ln \mathrm{C} / \partial \ln \mathrm{KPA}=1-\mathrm{c}$ has long run constant returns to scale over $x, K$ and also KPA ... because this expression is equal to:

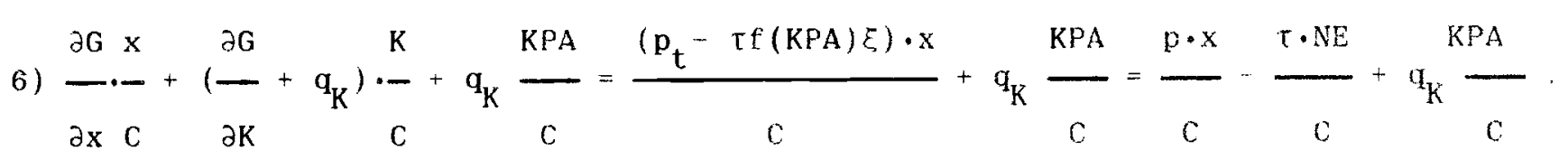
Since $p \cdot x / C$ is equal to one by definition and $\tau \cdot N E=q_{K} \cdot K P A$, this is clearly equal to one.

The specification of the cost function above can be used to derive a costside productivity measure, capturing $\partial \mathrm{ln} \mathrm{C} / \partial \mathrm{t}$, similarly to standard accounting productivity measures but adjusting for the fact that KFA is not a productive input. To accomplish this, it is first necessary to determine the total derivative of $\mathrm{C}$ with respect to time:

7) $\frac{d \ln C}{d t}=\frac{1}{C} \cdot\left(\frac{d G}{d t}+\frac{{d q_{K} K}_{d t}}{d t}+\frac{d q_{K} K P A}{d t}\right)$

$$
=\frac{1}{c} \cdot\left(\frac{\partial G}{\partial t}+\frac{\partial G}{\partial x} \frac{d x}{d t}+\frac{\partial G}{\partial K} \frac{d K}{d t}+\sum_{j} \frac{\partial G}{\partial q_{j}} \frac{d q_{j}}{d t}+K \cdot \frac{d q_{K}}{d t}+q_{K} \cdot \frac{d K}{d t}+K P A \cdot \frac{d q_{K}}{d t}+q_{K} \cdot \frac{d K P A}{d t}\right) .
$$

following Ohta [1975] the primal output-side measure of productivity - $\partial \ln x / \partial t$ as contrasted to the cost measure $\partial \ln \mathrm{C} / \partial \mathrm{t}-$ is equivalent to the cost measure with constant returns to scale and can be calculated from (7) by calculating dln C/dt directly from total cost $C=\sum_{j} q_{j} v_{j}+q_{K} \cdot K+q_{K} \cdot K P A$ to equate to (7):

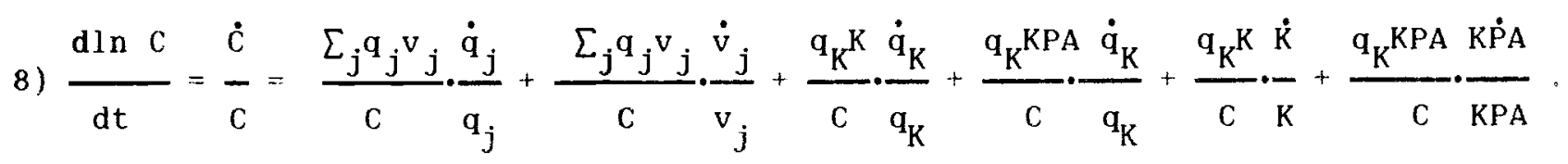


Setting these two expressions for dln $\mathrm{C} / \mathrm{dt}$ equal, solving for $\partial \mathrm{lnc} / \partial t$, and using Shephard's lemma results in:

9) $-\frac{\partial \ln c}{\partial t}=\frac{G_{x} \cdot x}{c} \frac{\dot{x}}{x}-\sum_{j} \frac{q_{j} v_{j}}{c} \cdot \frac{\dot{v}_{j}}{v_{j}}-\frac{q_{K} K \dot{K}}{c} \cdot \frac{\dot{K}}{\text {, }}$,

where $G_{x} \cdot x=p \cdot x-\tau \cdot N E$ by the first order conditions, so,

$$
\text { 10) } \begin{aligned}
-\frac{\partial \ln C}{\partial t} & =\left(\frac{p \cdot x-\tau \cdot N E}{c}\right) \cdot \frac{\dot{x}}{x}-\sum_{j} \frac{q_{j} v_{j}}{c} \cdot \frac{\dot{v}_{j}}{v_{j}}-\frac{q_{K} K \dot{K}}{c} \cdot \frac{\dot{K}}{c} \\
& =\left(\frac{p \cdot x-q_{K} \cdot K P A}{c}\right) \cdot \frac{\dot{x}}{x}-\sum_{j} \frac{q_{j} v_{j}}{C} \cdot \frac{\dot{v}_{j}}{v_{j}}-\frac{q_{K} K \frac{\dot{K}}{C}}{K}
\end{aligned}
$$

Note that $-\partial \ln \mathrm{C} / \partial \mathrm{t}$ is a positive number because cost diminution is equivalent to an increase in productivity.

This formula is straightforward to implement and intuitively feasible but is also based on a strong theoretical foundation. The fundamental adjustment to this expression from the standard expression

11) $-\frac{\partial \ln c}{\partial t}=\frac{\dot{x}}{x}-\Sigma_{j} \frac{q_{j} v_{j} \dot{v}_{j}}{c} \underbrace{}_{v_{j}}-\frac{q_{K}(K+K P A)}{c} \cdot \frac{(K+\dot{K} P A)}{K+K P A}$

is based on purging the effect of pollution abatement capital from the output measure, to capture marginal costs for the actual output, and removing the KPA component from the total capital stock, since KPA does not contribute to production and therefore productivity.

Note that the effect of the pollution abatement adjustment on productivity is ambiguous in sign; if productivity is incorrectly calculated as (11) instead of (10) the weight on the $\mathrm{dln} x / \mathrm{dt}$ term (which has a positive sign) is higher 
(one instead of one minus a positive number), the weight on the $\mathrm{dln} \mathrm{K} / \mathrm{dt}$ term (which has a negative sign) is higher, and the $\mathrm{d} l \mathrm{n} \mathrm{K} / \mathrm{dt}$ term is calculated as the change in total capital rather than just productive capital compared to the correct calculation in (10). The difference depends, therefore, on the relative magnitudes of the $d \ln x / d t, d l n k / d t$ and $d l n(K+K P A) / d t$ terms and cannot be unambiguously signed.

To more directly see the effect of the pollution abatement adjustment on productivity we subtract from (10) the standard expression (11). The resulting biás b is:

12) $\left.b=-\frac{q_{K} K P A}{c} \cdot \frac{\dot{x}}{x}-\frac{q_{K} K \dot{K}}{c} \cdot \frac{q_{K}(K+K P A)}{C}+\frac{\dot{K}}{K} \cdot \frac{K}{K+K P A}+\frac{K \dot{P A}}{K P A} \cdot \frac{K P A}{K+K P A}\right)$

$$
=\frac{\mathrm{q}_{\mathrm{K}} \mathrm{KPA}}{\mathrm{C}} \cdot\left(\frac{\mathrm{KPA}}{\mathrm{KPA}}-\frac{\dot{\mathrm{x}}}{\mathrm{x}}\right)
$$

If productivity is incorrectly calculated as in (11) instead of (10), the bias term is ignored. If growth of pollution abatement capital exceeds growth of output the standard expression underestimates productivity change. If KPA and $x$ grow by the same rate the bias b is zero; the downwards correction of the weight of output growth by the cost share of abatement capital equals the upwards correction by not subtracting in the adjusted measure the weighted growth of pollution abatement capital. 


\section{Empirical Results}

II I a. Data

The U.S. and Canadian manufacturing data for capital, labor and output prices and quantities respectively were provided by Berndt and wood [1984] and G.Campbell Watkins [1985]. The corresponding German data were provided by Unger [1985].

The pollution abatement capital data for the U.S. is based on data on capital stocks and expenditure (constant and current) for pollution abatement capital equipment presented in Kappler and Rutledge [1982]. This data was used to determine a beginning capital stock and investment over the period in pollution abatement capital. The price of capital was calculated from the zero profit condition as the ex-post price of the total capital stock, including $K$ and KPA. The Canadian pollution abatement capital data is more sparse. The data used is from the Statistics Canada publication water and Air Pollution Abatement Expenditures, which provides information on air and water pollution expenditures only for 1970-75. This data is, however, based on the class 24 and 27 CCA claims available in the Statistics Canada publication Corporation Taxation statistics. The data from this publication was therefore used to extrapolate the 1970-75 expenditure numbers forward and backward. The price index for pollution abatement capital was assumed to be equivalent to that for capital as a whole, since an ex-post price was used and it is not possible to distinguish between returns to the two individual capital inputs separately. For the German data, data collection on the costs of environmental protection regulations began in 1970 with the proclamation of an environmental protection program by the German government. The data on net investment for pollution 
abatement equipment for the years $1971 \cdots 75$ have been developed by the

Umwe ltbundesamt (Federal offjce for the Environment) in Berlin. Since 1975

these data have been published yearly by the Statistisches Bundesant. To

determine a capital stock series we made an assumption for the beginning capital stock in 1970 and cumulated these investment data according to the perpetual inventory method.

\section{I I . Results}

The productivity indexes calculated for the empirical comparison comprise indexes computed in a standard way including pollution abatement capital as part of the capital stock (as in (11)) and "adjusted" indexes (corresponding to (10)) which do not include pollution abatement capital as a productive input. These indexes were computed for the U.S. for 1960-80, Canada for 1967-80 and Germany for 1972-81 and are reported in Tables 1,2 , and 3 respectively. Only one "variable" input was considered, labor, so the indexes represent multifactor productivity growth for value added. The differences between the standard and adjusted measures were also calculated and are presented as the third columns of the tables. Summary information in terms of averages over selected time periods are reported at the bottom of the Tables.

The first point to note is that in all of these countries, especially the U.S. and Canada, response to regulations is spread out and often delayed as long as possible because penalties for non-compliance are, in practice, usually not very large. This makes it very difficult to pinpoint a particular year in which environmental regulations should begin to make a difference for productivity measures. In both North American countries, however, in the beginning of the 1970 's purposive environmental regulation at the Federal level really commenced; 
one would therefore not expect a large impact of environmental regulations on productivity measurements before this time. In Germany the timing is very similar; 1971 is the year in which the government became an active participant in environmental control. The impacts of environmental regulation should therefore take place approximately during the same time period and are closely comparable.

The U.S. indexes are presented in Table 1. These indexes provide interesting patterns to assess. Productivity growth was quite large on average throughout the 1960's, and, as would be expected, the impact of changes in pollution abatement capital expenditures was small. This implies from the discussion of the bias term "b" in the previous section that changes in output and pollution abatement capital did not deviate significantly, and/or that the cost share of KPA was small. Both appear to be true; the states were in charge of regulation of the environment during this time period and regulation was sparse. The impact also was in both directions; at times pollution abatement capital expenditures caused standard productivity measures to indicate stronger growth and sometimes weaker growth than those including only productive inputs, as would be expected from the interpretation of " $b$ ". Overall the KPA adjustment has a smoothing effect since in good years $\dot{x} / x$ exceeded $\dot{K P A} / \mathrm{KPA}$ so that the bias $b$ causes an overestimate of the standard measure, and vice-versa. On average the effect of including pollution abatement capital in productivity calculations becomes larger in the early 1970's once the EPA began to control these regulations. As hypothesized by most researchers, the standard practive of including pollution abatement capital in the productivity growth calculations appears to have a depressing effect on the evidence of productivity growth, although in general the impact is not large. The impact in 1970 of purging the productivity measure of the KPA-effect, for example, is an increase 
in measured productivity of .266 percentage points, causing the decrease in productivity in that year to reduce from $4.865 \%$ to $4.599 \%$, approximately a $5 \%$ change in the growth rate.

The only years in which this impact has the opposite sign -- productivity growth including KPA as a productive input appears better than without KPA incorporated - are 1972, 1976 and 1977, all years of higher than average productivity growth. In these years the impact of strongly increasing output growth, arising after a previous decrease in output, appears to overwhelm the small (and in some cases negative) changes in KPA and $K$. This is consistent with the interpretation of the bias "b", above.

The strongest impact of KPA adjustment are in those years when productivit growth is really catastrophic and where strong increases in KPA caused the bias term "b" to affect the standard productivity growth measure significantly. For example, 1974 and 1980 are extremely bad years for productivity growth and in both cases capital (and especially pollution abatement capital, KPA) increased dramatically while output stagnated or decreased. The adjusted index thus shows less decline in productivity growth than the standard index for these years.

Similar trends appear in the productivity growth indexes for Canada reported in Table 2 . Overall both the productivity growth fluctuations and impacts of adjustment for KPA are stronger for Canada than for the U.S. The years of the strongest impacts of pollution abatement capital purchases occur in 1970, 1975 and 1980 which are years of devastating productivity decreases; 1975 is particularly striking. This is consistent with the interpretation of the bias term $b$; in these recession years $\dot{x} / x$ and $\dot{k} / K$ became increasing smaller than $\mathrm{KPA} / \mathrm{KPA}$.

In addition, the high productivity growth in 1973 and sharp decline into 1974 and 1975 which in turn resulted in healthy productivity growth in 1976 to 
1979, is the same pattern, although stronger, that shows up in the U.S. indexes. For Canada in particular, however, in the post-1976 years the effect of pollution abatement capital purchases was minimal and, in fact, slightly contributed to evidence of large productivity growth because KPA was not increasing as it had in previous years whereas output growth was recovering.

One difference between the U.S. and Canadian indexes is that for the U.S. the difference between the standard and "adjusted" productivity indexes fluctuates whereas the Canadian numbers indicate a much stronger trend from fairly large and positive impacts of adjustment for KPA in the early 1970 's to small and then negative impacts of this adjustment in the later years. This suggests that especially for Canada productivity growth was greater in the beginning of the 1970 's than measured, but that the "recovery" after 1975 has been overstated. This is particularly evident in 1979; treating KPA as productive in the "standard" manner results in an almost.4\% increase in the productivity growth measure for that year as compared to the adjusted measure. One other tendency which is similar for the U.S. and Canada and which is consistent with the interpretation of the bias term "b" is that the depressing effect of including KPA as a productive input in productivity calculations is strongest in bad years. Productivity declines are muted with the KPAadjustment. The reverse clearly also tends to be true; as noted above the KPA adjustment smooths out peaks and troughs in the productivity indexes.

The tendencies discussed in the previous two paragraphs provide evidence that the acceleration effect - where environmental regulation facilitates economic growth through modernization of the existing capital stock -- may hold true. It appears from these numbers that strong economic growth is consistent with a KPA adjustment that is negative so that the net effect is that including KPA investment further increases productivity growth. This is a crude 
indicator, however, because the current model does not include any of these potential determinants of productivity. In addition, another type of impact which may be appearing in these indexes and is not included in the model is capacity utilization. The impact of KPA is cyclical, as the interpretation of the bias term "b" above indicates, which suggests an important impact of short run fixities of the capital stock which exacerbate productivity growth fluctuations. A final effect which this framework may encompass implicitly is the incentive to buy pollution abatement capital in "good" years because of special financial assistance for purchases of KPÁ in Canada. This is aiso true, perhaps to a lesser extent, in the U.S. and Germany.

As mentioned, the Canadian manufacturing numbers suggest a clearly timedependent impact of environmental regulation. In particular, although the impact of the regulations imposed on environmental discharges in the 1970 's does not occur in any one particular year -- the impact is spread out because of postponement of compliance with the restrictions - the Canadian data suggest that the largest negative impact on productivity growth as usually measured was in the beginning of the regulatory effort, especially in 1972 . After this time growth actually looks better with standard methods, like 1976 and 1977 in the U.S. This trend, and therefore the effect of swift compliance with the regulations, is more evident in Canada than the U.S.

The German indexes show this tendency even more strongly. The German productivity growth indexes in Table 3 cover a shorter time period -- from 1972 -- but indicate a strong effect commencing when regulations were imposed in 1971 and continuing for the first four years. The depressing effect of KPA investment on standard productivity measurements is quite substantial in the beginning, approximately .2\% to .3\% for each year from $1972-75$, even though all these years except 1975 otherwise were years of healthy productivity gains. 
After this period investment in KPA appears to have much less of an effect -the initial investments to satisfy the standards were completed. The KPA-effect becomes small and even negative by 1979, a year of good productivity growth, second only to 1976. The response to regulations in Germany therefore appears faster, perhaps because of better non-compliance penalties and thus swifter response.

Overall, the German productivity growth indexes provide evidence of much stronger and consistent productivity growth than in the U.S. and Canada, although the trends are similar. The one catastrophic -- negative productivity growth -- year was in 1975 and the other poor period was 1980-81, when the KPAadjustment becomes again more effective. The initial post-OPEC decrease in productivity growth appears later and was shorter-lived, however, than in the U.S. and Canada; the decrease is only for one year, 1975, and the following year showed the best productivity growth in the sample. This is the only productivity decline that can be compared throughout its cycle, since the data sample is so short.

The productivity growth indexes provided for the U.S., Canada, and Germany do not indicate any documentable evidence that competitiveness for the U.S. has declined relative to the other countries because of environmental regulations. In fact, the evidence suggests that Germany may have suffered more, at least from 1972 to 1975 from environmental regulations than did the U.S. or Canada. The impact on the U.S., however, from initial compliance with the regulations, does not appear to have ended, whereas the impacts on the other countries, Canada and Germany, has slowed considerably. Thus the U.S. may be in relatively worse shape from the late 1970's from late compliance with regulations.

Additional information on overall trends may be obtained from the summary statistics on average productivity growth rates provided at the ends of Tables 
1,2, and 3. The averages are presented for different years for the different countries because the sample periods vary. For the U.S. the partition is for 1960-67, 1967-72 and 1972-80, since the Canadian sample starts in 1967 and the German sample in 1972 , so corresponding divisions into the last two components are possible for Canada and the last partition can be captured in Germany. The dividing point often mentioned, however, is 1973. Therefore a partition at 1973 is also provided as possible for all countries. Finally, since the German data also includes 1981, corresponding average measures to 1981 instead of 1980 are also reported.

The U.S. averages do not provide evidence of a dramatic productivity slowdown in manufacturing on average since 1973. Although 1974 and 1975 were poor years for both the standard and adjusted productivity measures, 1973 and post-1975 were times of healthy productivity growth. Some associated evidence is available, however; productivity growth dropped from an average of $2.872 \%$ per year for the standard measure from 1960 to 1967 to $2.661 \%$ from 1967 to 1973 and 1.565\% from 1973 to 1980 . Much of this decline may be attributed to the poor productivity performance in 1980, since 1976-1978 at least were years of fairly large productivity growth.

The adjusted U.S. measures do "smooth" the productivity decline that is evident from the numbers, the 1960-67, 1967-73 and 1973-80 averages for this index are $2.865 \%, 2.743 \%$ and $1.788 \%$ respectively, indicating the same trend as before the adjustment but slightly muted. Overall the averages over the time period, however, indicate only a slight trend downward over time, a slight increase in measured productivity adjusted for KPA than for the standard measures, and much more fluctuation around the trend than changes in the trend.

The Canadian averages provide evidence of a stronger decline over time, although a substantial amount of this effect can be attributed to the 
catastrophic productivity decline in 1975 and increase in 1971 and, like the U.S. numbers, to the 1980 drop. Again, and even to a greater extent, the averages hide the large fluctuations in the complete indexes which have already been assessed. The average annual percentage growth rates for $1967-73$ and 197380 for the standard productivity calculations are $3.239 \%$ and $.229 \%$, respectively, indicating a large decline over time. The adjusted averages are slightly better, although the relative positions are not changed noticeably; the corresponding annual percentage increases are $3.360 \%$ and $.278 \%$, respectively.

Finally, the averages for Germany reflect the consistently high productivity captured in the indexes. The 1973-80 average annual productivity growth rate is $2.855 \%$, as compared to $1.788 \%$ and $.229 \%$ for the U.S. and Canada, respectively. The 1973-81 average is slightly worse due to the poor productivity performance in 1981, 2.555\%. Comparison of the entire German sample to the corresponding U.S. and Canadian numbers yields average annual growth rates of $2.828 \%$ as compared to $2.174 \%$ and $.858 \%$ respectively, which is slightly closer and appears quite respectable for the U.S. on average, although still very low for Canada.

The adjusted averages provide additional evidence of comparable growth between the U.S, and Germany and similar impacts of pollution abatement capital expenditures. The 1972-80 and 1973-80 percentage growth rates for the U.S. corresponding to the adjusted productivity growth rate index are $2.370 \%$ and $1.788 \%$, compared to $.918 \%$ and $.278 \%$ for Canada, and $2.963 \%$ and $2.974 \%$ for Germany respectively, all indicating greater average annual productivity growth with the depressing impacts of pollution abatement capital purchases removed. The percentage magnitudes are different, however; the adjustment is strongest for the U.S., with an average of an average of .2 percentage points added to the productivity measure with the KPA adjustment, second for Germany with 
approximately .12 percentage points, and smallest for Canada which already

exhibited the poorest productivity growth performance, about a . 05\% difference. The U.S. appears relatively unhindered by environmental regulation during this time period, therefore, compared to Canada and Germany, and the overal] productivity performance is very close to that in Germany.

\section{Concluding Remarks}

In this paper we have considered the often proposed suggestion that compliance with environmental regulations in the form of investment in "unproductive" capital, pollution abatement capital, KPA, has caused part of the observed "productivity slowdown" since the early $1970^{\prime} \mathrm{s}$ in industrial countries. In particular, we have considered the effects of emission or discharge standards, and resulting investment in KPA to satisfy these standards, on the measurement of productivity growth for the manufacturing sectors of the U.S., Canada and Germany. The overall conclusion is that this investment does appear to have depressed standard productivity growth measurements for these countries on average, although the effect was strongest for Germany in the earlier years of environmental concern and imposition of regulations, and is spread out and quite strong at the end of the period for the U.S., with Canada somewhere in between. This suggests that the impact on international competitiveness of environmental regulations has been to cause Germany's position to worsen in the early $1970^{\prime} \mathrm{s}$ relative to the U.S. and the reverse in the latter $1970^{\prime} \mathrm{s}$ and early $1980^{\prime}$ s, with, again, Canada being in the middle.

The approach employed in this study is very useful for justifying a method of adjusting productivity measures for environmental regulation effects, and explicitly providing a basis for the ambiguity of the direction of the impact 
which is recognized in the literature. The framework developed has much interpretative potential. For example, the contribution of investment to productivity in the $1970^{\prime}$ 's has been a controversial subject. Some researchers assert that investment decreases have been a large factor contributing to the productivity declines of the 1970 's and others say that investment really has not decreased and perhaps has even been too strong given the potential productivity of investment expenditures during this time period. The model used in this study shows that investment in productive capital has been less than that for measured capital and to what extent; this provides a foundation for the former assertion. In addition, the impact of environmental regulation on international competitiveness is clear within this structure; the differences in productivity between standard and adjusted productivity growth rates can be computed and compared between countries to see which countries have fared the worst in terms of productivity as a result of environmental concern and regulation.

Although the framework developed here is rich and provides theoretical justification for some assertions made in the literature, other hypotheses about the structure within which environmental legislation affects productivity growth may not be modeled and quantified using the type of nonparametric approach utilized here. For example, there are important indirect effects from control of pollution abatement technology which some authors have argued causes environmental regulation -- particularly in the U.S. ... to be inefficient $0 \mathrm{~S}^{\circ}$ cost-ineffective because of distortion of technical change and investment patterns. In reverse, incentives stemming from financial assistance for purchases of pollution abatement capital as compared to productive capital may distort investment decisions toward capital which may be classified as pollution abatement capital. Direct assessment of the associated costs and benefits of 
environmental regulation requires determination of a shadow value of pollution abatement capital which differs from that for productive capital. This, however, cannot be accomplished with the available data and a nonparametric framework since the ex-post returns only to total capital can be determined; the individual components cannot be separated.

Also, in terms of the specification of the model and particularly for international comparisons, the relevance of standards as the assumed regulatory instrument for all countries may be questionable. This is related to the point made in the previous paragraph; it may be that additional distorting types of regulatory instruments are used which cause the cost of pollution abatement capital to differ from the purchase cost and the shadow value to differ from the implied value on the margin. Again, this can only be dealt with if the shadow values can be distinguished. In the current context, the assumption of standards as the motivating regulatory force may be justifiable, since at least Canada and Germany rely substantially on environmental standards, in terms of flows of discharges or emissions, to motivate environmental control. The U.S. system too is based on a system of standards imposed by the Environmental Protection Agency although in practice the regulation is of ten in terms of specification of control techniques and does not have enough emphasis on costs. An empirical problem with assessment of effects of regulatory controls on productivity is that the impacts of pollution abatement capital appear to be cyclical. This may not pose difficulties if, for example, the cyclicity arises because firms make explicit decisions to postpone investment until "good times", but it may present problems if the appearance of strong regulatory impacts in peaks and troughs is simply a cyclical phenomena which should be purged from the measurement of productivity. 
These problems with the approach used in this study suggest that specification of an econometric model may facilitate consideration of important effects on production from environmental regulation. In particular, if a shortrun model is specified and estimated which is consistent with our theoretical structure, shadow values may be identified individually for the individual capital components and capacity utilization may be adjusted for. This may be an important avenue to pursue for future research.

This obviously cannot, however, be accomplished nonparametrically. Since nonparametric analysis is the most common way of calculating productivity growth rates, the current specification provides a very practical and therefore useful way of adjusting productivity measures for the impacts of environmental effects while still being based on an explicit theoretical optimization model for purposes of justifying the approach used for adjustment and providing interpretive power. 
Table 1

Value-Added Productivity Growth Indexes (\%) for U.S. Manufacturing Standard and KPA-adjusted Indexes and Differences

\begin{tabular}{lrrr} 
Year & $\begin{array}{l}\text { Standard } \\
\text { Productivity }\end{array}$ & $\begin{array}{r}\text { KPA-Adjusted } \\
\text { Productivity }\end{array}$ & \multicolumn{1}{c}{ Differenc } \\
1960 & 6.462 & & \\
1961 & 0.826 & 0.845 & 0.017 \\
1962 & 10.950 & 10.842 & -0.108 \\
1963 & -1.318 & -1.316 & 0.002 \\
1964 & 7.970 & 7.936 & -0.034 \\
1965 & 2.026 & 2.000 & -0.026 \\
1966 & -5.501 & -5.426 & 0.075 \\
1967 & 1.562 & 1.596 & 0.034 \\
1968 & 2.878 & 2.941 & 0.063 \\
1969 & 0.555 & 0.677 & 0.122 \\
1970 & -4.865 & -4.599 & 0.266 \\
1971 & 4.700 & 4.724 & 0.024 \\
1972 & 7.046 & 7.028 & -0.018 \\
1973 & 6.754 & 6.836 & 0.082 \\
1974 & -4.057 & -3.554 & 0.503 \\
1975 & -0.231 & -0.128 & 0.103 \\
1976 & 5.471 & 5.400 & -0.071 \\
1977 & 5.128 & 5.007 & -0.121 \\
1978 & 1.263 & 1.382 & 0.119 \\
1979 & 0.176 & 0.513 & 0.337 \\
1980 & -1.987 & -1.155 & 0.832
\end{tabular}

Averages

$\begin{array}{lll}1960-67 & 2.872 & 2.865 \\ 1967-72 & 1.979 & 2.061 \\ 1967-73 & 2.661 & 2.743 \\ 1972-80 & 2.174 & 2.370 \\ 1973-80 & 1.565 & 1.788\end{array}$


Table 2

Value-Added Productivity Growth Indexes (\%) for Canadian Manufacturing Standard and KPA-adjusted Indexes and Differences

$\begin{array}{lrrr}\text { Year } & \begin{array}{l}\text { Standard } \\ \text { Productivity }\end{array} & \begin{array}{l}\text { KPA-Adjusted } \\ \text { Productivity }\end{array} & \text { Differe } \\ 1967 & -3.599 & -3.478 & \\ 1968 & 4.052 & 4.158 & 0.121 \\ 1969 & 1.534 & 1.598 & 0.106 \\ 1970 & -8.973 & -8.806 & 0.064 \\ 1971 & 12.003 & 12.124 & 0.167 \\ 1972 & 5.891 & 6.039 & 0.121 \\ 1973 & 11.762 & 11.884 & 0.148 \\ 1974 & -3.045 & -2.883 & 0.122 \\ 1975 & -12.729 & -12.152 & 0.162 \\ 1976 & 4.213 & 4.267 & 0.577 \\ 1977 & 3.870 & 3.836 & 0.054 \\ 1978 & 3.730 & 3.443 & -0.034 \\ 1979 & 3.003 & 2.643 & -0.287 \\ 1980 & -8.969 & -8.838 & -0.360 \\ & & & 0.131\end{array}$

Averages

$\begin{array}{lll}1967-72 & 1.818 & 1.939\end{array}$

$\begin{array}{lll}1967-73 & 3.239 & 3.360\end{array}$

$\begin{array}{lll}1972-80 & 0.858 & 0.918\end{array}$

$\begin{array}{lll}1973-80 & 0.229 & 0.278\end{array}$ 
Table 3

Value-Added Productivity Growth Indexes (\%) for German Manufacturing Standard and KPA-adjusted Indexes and Differences

$\begin{array}{lccc}\text { Year } & \begin{array}{l}\text { Standard } \\ \text { Productivity }\end{array} & \begin{array}{l}\text { KPA-Adjusted } \\ \text { Productivity }\end{array} & \text { Difference } \\ 1972 & 2.617 & 2.876 & 0.259 \\ 1973 & 3.502 & 3.711 & 0.209 \\ 1974 & 2.552 & 2.767 & 0.215 \\ 1975 & -1.774 & -1.488 & 0.286 \\ 1976 & 6.041 & 6.136 & 0.095 \\ 1977 & 4.042 & 4.125 & 0.083 \\ 1978 & 2.892 & 2.960 & 0.068 \\ 1979 & 5.011 & 4.996 & -0.015 \\ 1980 & 0.573 & 0.588 & 0.015 \\ 1981 & 0.152 & 0.258 & 0.106\end{array}$

\section{Averages}

$\begin{array}{lll}1972-80 & 2.828 & 2.963 \\ 1973-80 & 2.855 & 2.974 \\ 1972-81 & 2.564 & 2.693 \\ 1973-81 & 2.555 & 2.673\end{array}$




\section{Bibliography}

Berndt, E.R., and M. Fuss (1985), "Productivity Measurement with Adjustments for Variations in Capacity Utilization and other Forms of Temporary Equilibria", Manuscript, July, forthcoming in the Journal of Econometrics.

Berndt, Ernst R., and David 0. Wood (1984), "Energy Price Changes and the Induced Revaluation of Durable Capital in U.S. Manufacturing During the OPEC Decade", Manuscript, MIT Center for Energy Policy Research, January .

Christainsen, G.B., and R.H. Haveman (1981), "The Contribution of Environmental Regulations to the Slowdown in Productivity Growth", in the Journal of Envi ronmental Economics and Management. 8, pp. 381-390.

Conrad, Klaus (1985), "An Incentive Scheme for optimal Pricing and Environmental Protection", Paper presented at the Fifth World Congress of the Econometric Society, Aug. 17-24, 1985, Cambridge, Massachusetts.

Crandall, R.W., (1981), "Pollution Controls and Productivity Growth in Basic Industries", in T.G. Cowing and R.E. Stevenson (eds.) Productivity Measurement in Regulated Industries, Academic Press, pp. 347-368.

Dasgupta, Partha (1982), The Control of Resources, Harvard University Press: Cambridge, Massachusetts.

Denison, Edward F. (1979), Accounting for Slower Economic Growth: The United States in the 1970's, Washington D.C.: The Brookings Institution.

Gollop, F.M., and Mark J. Roberts (1983), "Environmental Regulations and Productivity Growth: The Case of Fossil-fueled Electric Power Generation" Journal of Political Economy, Vol. 91, No. 4, pp. 654-673.

Kalt, J.P. (1985), "The Impact of Domestic Environmental REgulatory Policies on U.S. International Competitiveness", John F. Kennedy School of Government Energy and Environmental Policy Center Discussion Paper No. E-85-02.

Kappler, Frederick G. and Gary L. Rutledge [1982], "Stock of Plant and Equipment for Air and Water Pollution Abatement in the United States, 1960-81", Survey of Current Business, November 1982.

Lau, Lawrence J. (1978), "Applications of Profit Functions", in Production Economics: A Dual Approach to Theory and Applications, M. A. Fuss and D. McFadden, eds., North-Holland.

Meyers, J.G., and L. Nakamura (1980), "Energy and Pollution Effects on Productivity: A Putty-Clay Approach", New Developments in Productivity Measurement and Analysis, Kendrick (ed.), National Bureau of Economic Research 44 , The University of Chicago Press.

Norsworthy, J.R., M.J. Harper and K. Kunze (1979), "The Slowdown in Productivity Growth": Analysis of Some Contributing Factors", Brookings Papers on Economic Activity, 2, pp. $387 \cdots 421$. 
Statistics Canada (1978), "Water and Air Pollution Abatement Expenditures 1970 $75^{\prime \prime}$, Business Finance Divison, Financial, Taxation and General Research Section, August.

Statistisches Bundesamt, Fachserie 19, Reihe 3 , Investitionen fur Umweltschutz im Produzieren den Gewerbe, different issues since 1975 .

Umweltbundesamt, Berichte 9/83, "Struktur and Entwicklung der Umweltschutzindustrie in der Bundesrepublik Deutschland", Berlin 1983.

Unger, Rolg (1985), "Theorie und Messung der totalen Faktorproduktivitat, 1960 1981", Ph.D. Thesis, University of Mannheim.

Watkins, G.C. (1985), "The Relationship Between Energy and Other Production Inputs in Canadian Manufacturing Revisited", Prepared for Energy, Mines an Resources, Canada, by DataMetrics Ltd., March. 